\title{
INVESTASI SUMBER DAYA M ANUSIA DALAM MENINGKATKAN MUTU PENDIDIKAN DI INDONESIA
}

\author{
Hardianto $^{1}$, Nofriser ${ }^{2}$ \\ Prodi Pendidikan IPS FKIP, Universitas Pasir Pengaraian, Desa Rambah Kec. Rambah Hilir, Pasir \\ Pengaraian $^{1}$ \\ Prodi Kewirausahaan FE, Universitas Pasir Pengaraian, Desa Rambah Kec. Rambah Hilir, Pasir \\ Pengaraian $^{2}$ \\ E-mail: hardiantocally@gmail.com ${ }^{1}$ \\ nofriserrohul@gmail.com ${ }^{2}$
}

\begin{abstract}
The problems of education today can be classified into three main problems, namely equity, quality and relevance. This research method is literature study with editing, organizing and finding steps. Data analysis used deductive and inductive techniques. The results of the study are known to overcome educational problems, one of which is by investing in human resources. Investment in human resources will be able to increase the competitiveness of educational institutions. Human capital includes intellectual, emotional, social, fortitude and moral capital. Education is said to be of quality if it meets or exceeds customer expectations both internally and externally. Therefore, improving the quality of education needs to be done by encouraging educators and education staff to increase their knowledge about their work through training, workshops and further studies.
\end{abstract}

Keywords: Investment, Human Resource, Quality of Education.

\begin{abstract}
Abstrak
Permasalahan pendidikan dewasa ini dapat diklasifikasikan menjadi tiga permasalahan utama, yaitu pemerataan, kualitas dan relevansi. Metode penelitian ini adalah studi pustaka dengan langkah-langkah editing, organizing dan finding. Analisis data menggunakan teknik deduktif dan induktif. Hasil penelitian diketahui untuk mengatasi permasalahan pendidikan salah satunya dengan melakukan investasi sumber daya manusia. Investasi sumber daya manusia akan dapat meningkatkan daya saing lembaga pendidikan. Modal manusia meliputi modal intelektual, emosional, sosial, ketabahan dan moral. Pendidikan dikatakan bermutu apabila memenuhi atau melebihi harapan pelanggan baik internal maupun eksternal. Oleh karena itu peningkatan mutu pendidikan perlu dilakukan dengan mendorong tenaga pendidik dan kependidikan untuk meningkatkan pengetahuan tentang pekerjaannya mereka melalui pelatihan, workshop maupun studi lanjut.
\end{abstract}

Kata Kunci: Investasi, Sumber Daya Manusia, Mutu, Pendidikan. 
Saat ini banyak terdapat permasalahan yang berkenaan dengan pendidikan. Permasalahan umum pendidikan dewasa ini dapat diklasifikasikan menjadi tiga permasalahan utama. Permasalahan itu berkaitan dengan pemerataan pendidikan, permasalahan dengan kualitas pendidikan dan permasalahan relevansi pendidikan. Tiga permasalahan tersebut harus diatasi agar tujuan pendidikan dapat dicapai secara optimal.

Permasalahan pemerataan lebih ditekankan kepada kesempatan memperoleh akses pendidikan. Permasalahan pemerataan pendidikan dapat disebabkan kondisi geografis, motivasi mengikuti pendidikan dan pendistribusian guru (Aristo, 2019). Pemerataan pendidikan juga dapat terlihat dari Angka Partisipasi Kasar (Perdana, 2019). Sementara kualitas pendidikan Indonesia harus diakui masih tertinggal dibandingkan negara lain (Sinambela, 2017).

Untuk pendidikan tingkat sekolah dasar anak anak yang tidak bersekolah ditahun 2020 adalah 0,62. Tingkat SMP sederajat, anak-anak yang tidak bersekolah adalah 7,29 , sementara tingkat SMA sederajat anak-anak yang tidak bersekolah adalah 22,31 (BPS, 2020) Angka ini mengindikasikan bahwa pemerataan pendidikan masih perlu dioptimalkan. Akan tetapi pemerataan tentu saja tidak hanya dari konteks bisa sekolah, namun juga merata dari sisi kualitas pendidikan. Pemerataan kualitas pendidikan sampai saat ini masih belum bisa dirasakan oleh seluruh masyarakat. Secara umum masih terdapat ketimpangan pendidikan di jawa dan di luar jawa (Etahfiz.org, 2020)

Permasalahan kualitas pendidikan juga dirasakan saat ini. Kualitas pendidikan kita masih tertinggal dibandingkan dengan negara lain. Berdasarkan survei Programme for International Student Assessment (PISA) berdasarkan tingkat literasi, saat ini peringkat literasi Indonesia baru pada rangking 62 dari 70 negara yang disurvey (Diantoro, 2021). Berdasarkan sistem pendidikan, Indonesia berada pada peringkat 70 dari 90 negara (Khairifah, 2020). Peringkat ini menandakan bahwa kualitas pendidikan di Indonesia mesti ditingkatkan. Segala upaya harus dikerahkan oleh pemerintah dan semua pihak terkait agar pendidikan Indonesia dapat berada pada posisi yang lebih baik lagi.

Permasalahan relevansi pendidikan juga masih dirasakan dewasa ini. Hasil pendidikan belum relevan dengan kebutuhan pasar atau tenaga kerja. Saat ini jumlah sarjana yang menganggur masih tinggi. Bulan Februari Tahun 2021 diketahui hampir satu juta sarjana di Indonesia menganggur (BPS, 2021). Dari sumber yang sama diketahui bahwa pengangguran yang berasal dari tamatan SMA/umum berjumlah 2.305.393 orang. Tamatan SMK yang menganggur berjumlah 2.089.137 orang. Angka ini mengindikasikan bahwa pendidikan kita belum relevan dengan kebutuhan dunia kerja.

Tingkah laku atau sikap peserta didik juga dirasakan tidak relevan dengan adat dan budaya Bangsa Indonesia. Saat ini masih sering terjadi tawuran antar pelajar, banyaknya kekerasan yang dilakukan oleh peserta didik dan tindakan negatif lainnya.

Melihat permasalahanpermasalahan di atas, tentunya perlu segera dicarikan solusi untuk mengatasinya. Penulis menawarkan solusi agar dilakukan dan ditingkatkan "Investasi Sumber Daya Manusia Dalam Meningkatkan Mutu Lembaga Pendidikan". Banyak negara bisa melesat maju karena melakukan investasi utama dalam bidang pendidikan atau Sumber Daya Manusia (SDM). Rumusan masalah dalam artikel ini dibuat dalam bentuk pertanyaan, yaitu:

1. Apa yang dimaksud dengan investasi dalam pendidikan? 
2. Aspek aspek apa saja yang termasuk dalam peningkatan investasi sumber daya manusia?

3. Bagaimana investasi SDM dapat meningkatkan mutu pendidikan?

\section{METODE}

Penelitian ini dilakukan menggunakan metode studi kepustakaan. Metode kepustakaan adalah serangkaian kegiatan yang berkenaan dengan metode pengumpulan data pustaka, membaca dan mencatat serta mengolah bahan penelitian (Zed, 2008). Metode kepustakaan dipergunakan untuk memperoleh data yang bersifat teoretis dengan mencari informasi tertulis dan sistematis dari beberapa ahli yang dapat memperluas wawasan berpikir (Rukajat, 2018).

Pengumpulan data dilakukan dengan tiga Langkah yaitu editing, organizing dan finding. Editing yaitu pemeriksaan kembali data yang diperoleh terutama dari segi kelengkapan, kejelasan makna dan keselarasan makna antara yang satu dengan yang lain. Organizing yaitu mengorganisir data yang diperoleh dengan kerangka yang sudah diperlukan. Finding yaitu melakukan analisis terhadap hasil pengorganisasian data dengan menggunakan kaidah-kaidah, teori dan metode yang telah ditentukan sehingga ditemukan kesimpulan yang merupakan hasil jawaban dari rumusan masalah. Instrumen penelitian dalam penelitian ini adalah peneliti sendiri. Analisis data dilakukan dengan teknik deduktif dan induktif.

\section{HASIL DAN PEMBAHASAN}

\section{Investasi Dalam Pendidikan} Lembaga pendidikan perlu melakukan investasi untuk tetap eksis dalam memberikan pelayanan pendidikan. Investasi dapat dilakukan dengan membangun sarana prasarana baru, menyediakan alat peraga atau media pembelajaran baru ataupun menggunakan alat, teknologi atau sistem baru. Investasi yang ditanamkan diharapkan akan memberi nilai lebih terhadap kualitas pelayanan yang diberikan.

Selain yang berkenaan dengan faktor fisik di atas, investasi juga bisa dilakukan terhadap sumber daya manusia (human capital). Modal manusia meliputi jumlah SDM yang ada, pengetahuan maupun perilaku mereka. Hal ini sesuai dengan pendapat Becker, Wright, McMahan dan McWilliams dalam (Bhattacharya et al., 2014) yang menyebutkan the human capital of a fi rm is therefore a real asset. A fi rm's human capital includes the number of employees and their knowledge, skills, and behaviors.

Investasi dalam sumber daya manusia akan menjadikan investasi fisik di atas akan semakin berdaya guna. Apabila sumber daya manusia tidak dikembangkan, sementara sumber daya fisik lainnya tetap dibangun, maka akan sulit meraih hasil yang maksimal. Hal ini disebabkan sumber daya lain (fisik) akan sangat mudah ditiru oleh para pesaing. Sementara sumber daya manusia akan sulit ditiru oleh pesaing. Sumber daya manusia dalam lembaga pendidikan terdiri atas tenaga pendidik dan tenaga kependidikan.

Investasi dapat diartikan sebagai penanaman modal atau sejumlah dana yang dikeluarkan untuk memperoleh sesuatu. Dalam kaitannya dengan investasi sumber daya manusia maka dapat diartikan sebagai dana yang dikeluarkan untuk meningkatkan kemampuan manusia agar setelah selesainya proses investasi diharapkan memberikan balikan yang optimal.

Untuk meningkatkan kualitas lembaga pendidikan, maka investasi terhadap manusia mutlak diperlukan. Hasil penelitian Abdullah menyatakan bahwa pertumbuhan ekonomi dipengaruhi oleh keberadaan human capital (Abdullah, 2014). Peningkatan human capital yang diaplikasikan melalui pendidikan, perilaku, dan sikap sebagai modal manusia dapat berdampak dan 
berimplikasi terhadap pertumbuhan ekonomi. Dalam konteks lembaga pendidikan tentunya dengan menerapkan human capital akan menguntungkan lembaga dalam meningkatkan pelayanan kepada pelanggan.

Pemahaman akan investasi manusia dapat dilihat dari beberapa indikator kegiatan yang dapat meningkatkan kapabilitas manusia, mengemukakan bahwa indikator tersebut adalah:

1) Health facilities and services, broadly conceived to include all expenditures that affect the expentancy.

2) On the job training, including old style appreticeship organized by firm;

3) Formally organized education at the elementary, secondary, and higher levels;

4) Study programs for adults that are not organized by firms, including extension programs notably in agriculture;

5) Migration of individuals and families to adjust to changing job opportunities; (Blaug, 1968).

Untuk menwujudkan lembaga pendidikan yang bermutu seluruh komponen mesti diperbaiki kualitasnya. Perbaikan sarana fisik memang penting akan tetapi investasi dalam SDM jauh lebih penting. Investasi SDM akan dapat mengoptimalkan sumber daya lainnya. Membangun SDM akan meningkatkan efektifitas dan efisiensi investasi bidang lainnya. Sementara investasi bidang lain tanpa membangun SDM akan rentan terhadap kehancuran dan inefisiensi.

\section{Aspek-Aspek Dalam Meningkatkan Human Capital}

Untuk meningkatkan human capital dalam lembaga pendidikan, kemampuan tenaga pendidik dan kependidikan yang perlu ditingkatkan adalah kemampuan intelektual, kemampuan teknis pekerjaan dan kemampuan sosial. Kemampuan intelektual berkenaan dengan kemampuan intelegensinya atau penguasaan kognitif terhadap pekerjaannya. Kemampuan teknis merupakan kemampuan yang mengarah kepada keterampilan dalam melakukan pekerjaan. Sementara kemampuan sosial berkaitan dengan kemampuan membina hubungan dengan sivitas akademika yang lain.

Dalam konteks pemberian pelayanan kepada stakeholder, maka mutu layanan yang diberikan sekolah harus selalu ditingkatkan terus menerus (Chair, 2019). Kebutuhan dan harapan stakeholder yang berubah menjadikan kualitas layanan harus berubah pula. Semakin tinggi kualitas layanan, maka semakin terpercaya lembaga pendidikan tersebut.

Lebih lengkap Winarno dan Sri Wahyuni (Winarno \& Wahyuni, 2015) mengemukakan bahwa human capital yang perlu dikembangkan itu meliputi: (1) modal intelektual, (2) modal emosional, (3) modal sosial, (4) modal ketabahan, dan (5) modal moral. Selain yang dijelaskan di atas, modal emosional lebih menekankan bagaimana tenaga pendidik atau kependidikan ini bisa cerdas mengelola emosionalnya. Tidak cepat tersinggung dan bisa bekerja dibawah beban pekerjaan yang banyak.

Patrick M. Wright dkk (2013) mengemukakan dimensi human capital adalah ability, personality, skill, knowledge, affect dan behavior. Dengan investasi terhadap manusia, diharapkan para pendidik dan tenaga kependidikan memiliki enam dimensi yang kuat dalam diri mereka. Dengan memiliki enam dimensi tersebut akan menjadikan personalia akan kreatif dan tidak mudah menyerah apabila menghadapi kendala dalam pekerjaan. Dimensi-dimensi tersebut akan menjadikan modal yang kuat untuk mewujudkan lembaga pendidikan yang bermutu.

3. Investasi Sumber Daya Manusia Dalam Meningkatkan Mutu 
Investasi secara sederhana berarti menanamkan modal (dana maupun tenaga) sehingga dari hasil investasi itu diharapkan memperoleh keuntungan yang jauh lebih baik dibandingkan sebelum investasi dilakukan. Dalam kaitan dengan investasi SDM (human capital) maka langkah awal yang perlu diperhatikan adalah proses rekrutmen yang dilakukan.

Rekrutmen menurut Castetter adalah suatu rangkaian kegiatan dalam pengelolaan ketenagaan yang dirancang untuk memperoleh tenaga dalam jumlah dan mutu yang dibutuhkan untuk melaksanakan tugas-tugas yang ada dalam sistem sekolah (Widodo, 2015). Semakin berkualitas sumber daya manusia (tenaga pendidik dan tenaga kependidikan) yang direkrut, akan semakin sedikit investasi yang perlu ditanamkan untuk meningkatkan kemampuannya. Semakin kurang berkualitas hasil rekrutmen, maka akan semakin banyak investasi yang perlu dikeluarkan.

Setelah rekrutmen dilakukan para tenaga pendidik dan tenaga kependidikan perlu diberikan peningkatan kemampuan dan wawasan dengan pemberian kesempatan mengembangkan diri. Minimal setiap tahun para tenaga pendidik dan kependidikan diberikan satu kali pelatihan atau pembekalan lainnya sehingga kemampuan mereka semakin terasah dan meningkat. Peningkatan kemampuan tersebut dapat dilakukan dengan mengirim personil ke luar lembaga atau mengadakan pelatihan tersebut di lembaga masing-masing.

Terdapat dua cara yang bisa dilakukan oleh sekolah untuk melakukan investasi SDM, yaitu:

1. Memberikan kesempatan melanjutkan pendidikan

Pendidikan (formal) dalam suatu organisasi adalah suatu proses pengembangan kemampuan ke arah yang diinginkan oleh organisasi yang bersangkutan (Notoatmodjo, 2009). Lembaga pendidikan mesti mendorong tenaga pendidik dan kependidikannya untuk melanjutkan pendidikan. Investasi melalui pendidikan akan lebih menguntungkan dibandingkan investasi fisik. Suryadi mengemukakan Investasi Sumber Daya Manusia melalui pendidikan memiliki dampak yang paling besar terhadap kemajuan negara-negara industri baru, dibandingkan investasi fisik (Ali \& Hayati, 2016).

Sesuai aturan perundangundangan, bahwa untuk menjadi guru minimal berkualifikasi S1 dan untuk menjadi dosen undang-undang mengamanatkan minimal berkualifikasi S2. Sampai saat ini masih banyak guru yang belum berkualifikasi S1 atau dosen yang belum S2. Menurut statistik data Kemendikbud jumlah guru seluruh Indonesia saat itu tercatat berjumlah 2.698.103 orang dan yang belum sarjana berjumlah 248.827 orang (Slamet, 2020).

2. Memberikan kesempatan mengikuti pelatihan/ workshop dan sejenisnya

Investasi SDM lainnya adalah dengan memberikan kesempatan mengikuti pelatihan, seminar atau workshop. Mengikuti pelatihan, seminar atau workshop biasanya tidak membutuhkan waktu yang banyak. Pimpinan hendaknya memberikan peluang dan bantuan bagi setiap tenaga pendidik dan kependidikan yang ingin mengikuti pelatihan/ seminar.

Tenaga pendidik dan kependidikan yang senior dan telah memiliki kualifikasi minimal juga perlu diberikan pengayaan dan penambahan informasi melalui pelatihan atau seminar. (Notoatmodjo, 2009) mengemukakan dua macam pelatihan yang bisa diberikan kepada karyawan (tenaga pendidik dan kependidikan), yaitu pre service training dan in service training. 
Sementara In service training dibedakan atas off the job side training dan on the job training. Apapun jenisnya pimpinan harus mendukung secara maksimal ketika para tenaga pendidk dan kependidikan ingin mengikutinya.

Memberikan kesempatan melanjutkan pendidikan dan mengikuti pelatihan akan sangat membantu dalam mewujudkan lembaga pendidikan yang berkualitas. Upaya itu juga akan membantu tenaga pendidik dan kependidikan mewujudkan karir yang cemerlang. Pembinaan karir tidak bisa hanya tanggungjawab pribadi tenaga pendidik/ kependidikan saja melainkan juga tanggungjawab lembaga. (Widodo, 2015) mengemukakan bahwa pengembangan karir akan dapat berjalan dengan baik apabila semua pihak yang berkepentingan menaruh perhatian dan mau bertanggungjawab terhadap semua kegiatan dan kebutuhan yang diperlukan dalam proses pembinaan karir.

\section{SIMPULAN DAN SARAN Simpulan}

Investasi dalam Lembaga Pendidikan untuk mewujudkan Pendidikan yang bermutu dapat dilakukan dengan investasi fisik (infrastruktur) dan nonfisik (manusia). Aspek atau komponen human capital yang mesti dikembangkan diantaranya intelektual, emosional, sosial, ketabahan dan moral. Investasi SDM (human capital) dalam mewujudkan pendidikan yang bermutu dapat dilakukan dengan memberikan kesempatan dan dorongan bagi tenaga pendidik dan tenaga kependidikan untuk melanjutkan pendidikan dan mengikuti pelatihan, seminar atau workshop.

\section{Saran}

Disarankan kepada kepala dinas pendidikan, kepala sekolah untuk memberikan kesempatan kepada tenaga pendidik dan kependidikan untuk melanjutkan pendidikan atau mengikuti seminar.

\section{DAFTAR RUJUKAN}

Abdullah, H. (2014). Realokasi Kebijakan Fiskal: Implikasi Peningkatan Human Capital dan Pembangunan Infrastruktur Terhadap Perrtumbuhan Ekonomi Kesejahteraan Masyarakat. Jurnal Bina Praja, 6(2), 117-128.

Ali, H., \& Hayati, E. (2016). Efektifitas Bantuan Finansial dari Pemerintah Aceh untuk Perguruan Tinggi Swasta terhadap Peningkatan Kualitas Pendidikan di Kabupaten Aceh Singkil. Serambi Academika, 4(2), 57-66.

Aristo, T. J. V. (2019). Analisis Permasalahan Pemerataan Pendidikan di Kabupaten Sintang. Jurnal Akuntabilitas Manajemen Pendidikan, 7(1), 25-34.

Bhattacharya, M., Doty, H., \& Garavan, T. (2014). The Organizational Context and Performance Implications of Human Capital Investment Variability. Human Resource Development Quartely, 25(1), 87-117.

Blaug, M. (1968). Economics of Education 1. Penguin Books.

BPS. (2020). Angka Anak Tidak Sekolah Menurut Jenjang Pendidikan dan Daerah Tempat Tinggal. Https://Www.Bps.Go.Id/Indicator/2 8/1984/1/Angka-Anak-TidakSekolah-Menurut-JenjangPendidikan-Dan-Daerah-TempatTinggal.Html.

BPS. (2021). Sarjana yang Menganggur Hampir 1 Juta Orang. Https://Databoks.Katadata.Co.Id/Da tapublish/2021/05/31/Bps-SarjanaYang-Menganggur-Hampir-1-JutaOrang-Pada-Februari-2021.

Chair, M. (2019). Manajemen Mutu Layanan Pada Sekolah Menengah. Jurnal Visi Ilmu Pendidikan, 11(2), 
66-75.

Diantoro, S. (2021). Tingkat Literasi Indonesia di Dunia Rendah, Rangking 62 dari 70 negara. Https://Perpustakaan.Kemendagri.G o.Id/?P=4661.

Etahfiz.org. (2020). Solusi Mengatasi Permasalahan Ketimpangan Kualitas Pendidikan Perguruan Tinggi Jawa dan Luar Jawa. Https://Etahfizh.Org/SolusiMengatasi-PermasalahanKetimpangan-Kualitas-PendidikanPerguruan-Tinggi-Jawa-Dan-LuarJawa/.

Khairifah, V. (2020). Sistem Pendidikan Terbaik di Dunia ada di 10 Negara Ini.

Https://Www.Cekaja.Com/Info/Sist em-Pendidikan-Terbaik-Di-Dunia.

Notoatmodjo, S. (2009). Pengembangan Sumber Daya Manusia. Rineka Cipta.

Perdana, N. S. (2019). Implementasi PPDB Zonasi Dalam Upaya Pemerataan Akses dan Mutu Pendidikan. Jurnal Pendidikan Glasser, 3(1), 78-92.
Rukajat, A. (2018). Pendekatan Kualitatif dan Kuantitaf (Research Approach). DeePublish, Yogyakarta.

Sinambela, L. P. (2017). Profesionalisme Dosen dan Kualitas Pendidikan Tinggi. Jurnal Populs, 2(4), 579596.

Slamet. (2020). Jumlah Guru di Indonesia.

Https://Kompaspedia.Kompas.Id/Ba ca/Infografik/Peta-Tematik/JumlahGuru-Di-Indonesia.

Widodo, S. E. (2015). Manajemen Pengembangan Sumber Daya Manusia. Pustaka Pelajar.

Winarno, \& Wahyuni, S. (2015). Pengaruh Modal Manusia dan Pembelajaran Organisasi Terhadap Kinerja yang Dimediasi oleh Kompetensi Organisasi. Buletin Ekonomi, 13(1), 97-108.

Zed, M. (2008). Metodologi Penelitian Kepustakaan. Yayasan Obor, Jakarta. 